This document is published in:

Journal of Industrial Economics (1998), 46(3), 301-315.

DOI: 10.1111/1467-6451.00073

(C) 1998 Blackwell Publishers Ltd. 


\title{
MARKET POWER AND MULTIMARKET CONTACT: SOME EVIDENCE FROM THE SPANISH HOTEL INDUSTRY*
}

\author{
Nerea Fernández† And Pedro L. Marín†
}

\begin{abstract}
This paper analyses the effect of multimarket contact on firms' behaviour. According to Bernheim and Whinston [1990], firms that meet in several markets for an infinite number of periods may find it profitable to redistribute market power among markets where they are operating. We present evidence supporting this prediction by using data from the Spanish hotel industry. Moreover, we also find that the omission of variables measuring multimarket contact creates a downward bias on the effect of concentration on prices. This result questions previous conclusions about the role of competition in industries where multimarket behaviour is expected.
\end{abstract}

\section{INTRODUCTION}

Multimarket competition is defined as 'a situation where firms compete with each other simultaneously in several markets' (Karnani and Wernerfelt [1985]). This situation is present in multiproduct industries or industries with different geographic markets. While the literature has concentrated on different aspects of this phenomenon, such as the presence of economies of scope, demand externalities and cross-subsidization, the effect of multimarket competition on the presence of tacit collusion has received little attention. The possibility that multimarket contact could promote anticompetitive outcomes was first raised in 1955 by Corwin Edwards, who wrote:

'When one large conglomerate enterprise competes with another, the two are likely to encounter each other in a considerable number of markets. The multiplicity of their contact may blunt the edge of their competition'.

\footnotetext{
* This is an extensively revised version of Nerea Fernández's MSc Dissertation at CEMFI. We would like to thank Miguel Benavente, Samuel Bentolila, Javier Campos, Javier Gimeno, Richard Green, Jonathan Haskel, A. Jorge Padilla, Richard Sicotte, Michael Waterson and seminar participants at CEMFI, Universidad Carlos III and the Warwick Summer Workshop 1996 on Modelling Firm Behaviour for their helpful suggestions. We are also grateful to the Instituto de Estudios Turísticos and the Bank of Spain Research Department for providing us with the raw data. Pedro L. Marín gratefully acknowledges financial support from Generalitat Valenciana (GV-3140/95). The usual disclaimer applies.

$\dagger$ Authors' affiliation: Nerea Fernández, BBV, Unidad de Análisis de Mercados, Clara del Rey 26, 28002 Madrid, Spain email:mrosa.morales@grupo.bbv.com

† Pedro L. Marín, Universidad Carlos III, C./Madrid 126, Getafe-28903 (Madrid), Spain email:marin@eco.uc3m.es
} 
This traditional view about the effects of multimarket contact has been recently revised by Bernheim and Whinston [1990], who analyze in detail the effects of multimarket contact on firms' behaviour. In their model, firms expect to compete over an infinite number of periods in a set of different markets and the penalty for deviating from the collusive outcome in any market $k$ is felt in all markets where the deviating firm meets its market $k$ rivals. They show that the existence of this contact may imply that firms not only increase their power to collude in general terms but they may also find it profitable to design strategic policies and redistribute market power among markets where they are operating, so that total profit maximization can be achieved by giving up profits in markets where more collusive outcomes are reachable in order to facilitate collusion and increase profits in more competitive markets.

The main assumptions needed for this type of result to hold are the following. First, there is a set of firms operating in several markets or product lines and some of these firms meet in more than one market. Second, full collusion is not achievable in at least one market, i.e., any firm would have incentives to deviate from the fully collusive strategy given the other players' strategies. Third, either markets differ in some characteristics that affect the outcome of the game, such as the number of competitors and the toughness of competition, or firms have market specific characteristics such as their cost structure. In other words, if the same firms were competing in identical markets, the equilibrium would not be affected by the existence of multimarket contact. On the other hand, the result is robust to changes in the firms' choice variable, the shape of the cost and demand functions and the length and toughness of the penalty imposed on deviating firms.

Phillips and Mason [1992] conduct a series of experiments which support these results. Additionally, a few empirical papers have attempted to measure the multimarket contact effects. For instance, Evans and Kessides [1994] examine empirically the effects of multimarket contact on pricing in the US airline industry. The analysis of the time-series and crosssectional variability of airline fares in the largest US city-pair routes reveals that fares are higher in city-pair markets served by carriers with extensive inter-route contacts. Similarly, Parker and Röller [1997] estimate a structural model of firms' behaviour in the mobile telephone industry and find that multimarket contact significantly increases collusion. However, none of these papers tests Bernheim and Whinston's hypothesis about the strategic effects of multimarket contact.

The approach we consider in the paper is as follows. Consider a set of firms that operate and meet in more than one market. Assume that these firms expect to play an infinitely repeated game in each market that is determined by the characteristics of the firms and the market under study (the focal market) and also by the number of contacts and the 
characteristics of the market where the contacts take place (the contact market). Accordingly, we can write the equilibrium value for the choice variable as the result of three multiplicative components, namely its equilibrium value in the stage game, a term depending on the discount factor, and one depending on the degree of multimarket contact and the ease of collusion in both the focal and the contact market. To proxy multimarket contact for one specific firm and market, we aggregate the number of contacts that the firm has in other markets with its competitors in the focal market, giving different weights to the contact depending on the characteristics of the market where it takes place.

For the empirical test of multimarket contact effects, we use a data set from the Spanish hotel industry which includes all the hotels and boarding houses with three or more stars operating in Spain. Our decision has been based on the importance of the chains operating in this industry, with almost 33\% of the hotels belonging to a chain. We use a cross-section data base describing the prices and characteristics of 2221 hotels and boarding houses across 83 different geographic markets in Spain in 1996. ${ }^{1}$ With this data set, we estimate the effect of multimarket contact on prices by using the generalized least squares estimation procedure.

We obtain two main results. First, our analysis of the data reveals that the omission of variables measuring multimarket contact creates a downward bias on the effect of concentration on prices. Second, the evidence gives strong support to Bernheim and Whinston's hypothesis that in the presence of multimarket contact, prices rise in markets where it is difficult to collude and decrease in markets where it is easier to achieve collusive outcomes.

\section{REVIEW OF THE LITERATURE}

It is a well known result that firms can achieve more collusive outcomes when they expect to meet and compete for an infinite number of periods. To achieve these outcomes, the firms involved must design a set of penalties for deviating players. For instance, if a firm decides to deviate from the collusive outcome, the penalty imposed could consist of reverting for the remainder of the game to the equilibrium strategy for the stage game, since this is also a subgame perfect equilibrium in the repeated game.

Assume a market where $N$ firms producing differentiated products compete in prices and denote the equilibrium prices in the one shot game by $p_{i}^{*}, i=1, \ldots, N$. Consider this as the stage game of an infinitely repeated game. Now firms have the possibility of choosing a set of

\footnotetext{
${ }^{1}$ See the Appendix.
} 
alternative prices. Denote by $p_{i}^{\prime}$ the price for firm $i$ which maximizes the present discounted value of the firm's expected flow of profits subject to the following incentive constraint

$$
\pi_{i}^{\prime} \frac{1}{1-\delta} \geq \pi_{i}\left(R_{i}\left(p_{-i}^{\prime}\right), p_{-i}^{\prime}\right)+\pi_{i}^{*} \frac{\delta}{1-\delta}
$$

where $\pi_{i}^{*}$ and $\pi_{i}^{\prime}$ are firm $i$ 's profits when prices are $p_{i}^{*}$ and $p_{i}^{\prime}$ respectively, $\pi_{i}\left(R_{i}\left(p_{-1}^{\prime}\right), p_{-i}^{\prime}\right)$ are firm $i$ 's profits when all firms other that $i$ set their collusive prices, $p_{-i}^{\prime}$, and firm $i$ chooses its best response to them, $R_{i}\left(p_{-i}^{\prime}\right)$, and $\delta \in(0,1)$ is the discount factor.

Notice that given product heterogeneity the maximum sustainable price, denoted by $p_{i}^{+}$, is an increasing function of the discount factor, $\delta .^{2}$ Assuming that firms set $p_{i}^{\prime}=\min \left\{p_{i}^{m}, p_{i}^{+}\right\}$, where $p_{i}^{m}$ is firm $i$ 's monopoly price, then $p_{i}^{\prime}$ is a non decreasing function of $\delta$. At any given $\delta, p_{i}^{\prime}$ will depend on the same cost and demand conditions that determine $p_{i}^{*}$. Accordingly we could express $p_{i}^{\prime}$ as a separable function of the equilibrium price in the stage game and a function of the discount factor, $p_{i}^{\prime}=\Phi(\delta) p_{i}^{*}$, where $\Phi(\delta) \in\left[1, \frac{\min \left\{p_{i}^{m}, p_{i}^{+}\right\}}{p_{i}^{*}}\right]$.

Bernheim and Whinston [1990] generalize this analysis to cases in which firms meet and compete in more than one market, i.e., there is multimarket contact. The crucial assumption here is that any firm that breaks the collusive agreement in any market $k$ triggers the penalty in all the markets where it meets its market $k$ rivals. Assuming $K$ different markets, the incentive constraint becomes:

$$
\sum_{k=1}^{K} \pi_{i k}^{\prime} \frac{1}{1-\delta_{k}} \geq \sum_{k=1}^{K}\left\{\pi_{i k}\left(R_{i k}\left(p_{-i k}^{\prime}\right), p_{-i k}^{\prime}\right)+\pi_{i k}^{*} \frac{\delta_{k}}{1-\delta_{k}}\right\}
$$

i.e., given that the punishment is going to spread over all the markets, when a firm decides to deviate from the collusive outcome it does so in all the markets where it operates.

From this expression Bernheim and Whinston [1990] derive several interesting results. Firstly, for identical markets and firms' characteristics across markets, both profits and losses from deviating are multiplied by the number of markets where the firms are meeting, and the set of strategies that form subgame perfect equilibria remains unchanged. This is denoted as the irrelevance result.

Secondly, when markets differ or firms have market specific characteristics, we can obtain a larger set of equilibria for each market that still includes all the equilibrium strategies available in absence of multimarket contact. In particular, a firm can reach more collusive outcomes in some markets by violating condition (1) so long as this condition holds in other

\footnotetext{
${ }^{2}$ See Bernheim and Whinston [1990].
} 
markets as a strict inequality, i.e., when $p_{i}^{+}>p_{i}^{m}$, and condition (2) holds for the whole set of markets where the firm operates.

Thirdly, firms can do more than this. Assume that condition (1) holds as an equality for all the markets where the firm is operating, i.e. in all the markets $p_{i}^{+}<p_{i}^{m}$. In this case, firms can reduce their price in some markets so that condition (1) in these market holds now as a strict inequality. By doing so they can increase prices in other markets, violating condition (1), as long as condition (2) still holds. In fact, Bernheim and Whinston [1990] show that firms may find it profitable to reduce their prices in markets where they achieve more collusive outcomes in order to increase them in other markets with more competition as long as the extra profits from the second set of markets are greater than the profits forgone in the first set of markets. This is the most common case since for most demand and cost functions the number of units affected by the change in prices is smaller in the former than in the latter set of markets.

Thus, the existence of multimarket contact not only implies that firms may increase their power to collude in general terms but also that they may strategically transfer their power to collude from very collusive markets to other markets where collusion is more difficult to sustain. Accordingly, we can represent firm $i$ 's equilibrium price in market $k$ as

$$
p_{i k}^{\prime}=\Gamma\left(M M C_{i k}\right) \Phi\left(\delta_{k}\right) p_{i k}^{*}
$$

where $\Gamma\left(M M C_{i k}\right)$ measures the effect of multimarket contact. According to Bernheim and Whinston's [1990] predictions, we expect to observe $\Gamma\left(M M C_{i k}\right)>1$ in markets with less ease of collusion and $\Gamma\left(M M C_{i k}\right)<1$ in markets with greater ease of collusion.

\section{ECONOMETRIC SPECIFICATION}

The behaviour of the firms in the hotel industry can be represented according to a sequential decision process. At the first stage, firms decide if they want to open an establishment in a particular location and simultaneously they choose their capacity and quality in that location. Table AI in the Appendix reveals that firms do not change either capacities or qualities for very long periods so that these can be regarded as long run decision. At the second stage, firms compete in prices and earn profits. This process can be solved by backward induction. When competition takes place at the last stage, firms take the establishments' locations, capacities and qualities as given.

In the previous section we have shown that in the context of an infinitely repeated game, the equilibrium price for firm $i$ in market $k, p_{i k}^{\prime}$, can be represented as a function of its equilibrium price in the stage game, $p_{i k}^{*}$, a mark-up on this price which depends on the discount factor, $\delta$, and one term depending on the degree of multimarket contact and the ease of 
collusion in both the focal and the contact market. In turn, the set of $p_{i k}^{*}$ is determined by the cost function, $c\left(q_{i k}, w_{i k}\right)$, which depends on the level of output and the input prices, and market and product characteristics such as the price-demand elasticity, $\eta_{i k}$, the market concentration, $H_{k},{ }^{3}$ and the product's quality, $u_{i k}$.

The exogenous variables which try to measure all the arguments mentioned above are the following. ${ }^{4}$ Among the cost variables we include the variable $D D$ to measure market demand. This variable is included in the regression as an instrument for the firm's sales which are clearly endogenous. To avoid further endogeneity problems in the regressions, we include one period lagged values for this variable. At the same time, this variable controls for market differences that could affect the discount factor, $\delta$, for example, the level of demand may affect firms expectations about the future. We also include the variable Wages to measure input prices as labour is the most important input in the industry. The variable Wages is measured at the market level so it does not account for differences among firms in the same market. Accordingly, this variable should be interpreted as a market variable that could also be proxying exogenous characteristics related to market economic activity.

The variable Dist proxies firm i's price-demand elasticity. This variable is a normalized measure of the average distance in terms of product category between any given establishment and its rivals in the same geographical market. Therefore, it proxies the degree of substitutability for firm i's services in the same area. Larger values of Dist imply that firm $i$ 's rivals supply worse substitutes for the firm's services and so firm $i$ faces a less elastic demand. We did also control for other characteristics that could measure price-demand elasticity such as the nature of the market but none of them turned out to be significant so that we dropped them out from the final specification of the model. ${ }^{5}$

Concentration in market $k$ is measured by the variable $H I$. This variable is an instrument for the Herfindahl index of concentration which is potentially endogenous since it includes firm $i$ 's own sales in the market. To solve this problem we use capacity installed as an instrument for sales. Capacity is highly correlated with sales while it cannot be correlated with

\footnotetext{
${ }^{3}$ For a wide class of oligopolistic competition models there exists a non positive relationship between market concentration and price. The joint profit maximization model can be regarded as a limiting case in which prices do not change after the entry of new competitors. Bertrand with homogeneous goods can be regarded as the other limiting case since the entry of a second firm drives prices down to marginal costs. For the remaining models prices fall with market concentration (see Sutton, [1991]).

${ }^{4} \mathrm{~A}$ detailed definition of all the variables included in the empirical model is provided in the Appendix.

${ }^{5}$ For instance we included a set of dummy variables for different types of markets such as business cities, sea-resorts, high mountain-resorts, rural areas and historical towns, but their coefficients were not significantly different from each other.
} 
the error term since it is a long run decision given to the firm when it sets its prices. Accordingly we construct $H I$ as a Herfindahl index using the capacity values.

Two variables measure the quality of the hotel. First, its reported category in the Tourist Guide, which we call Category. Second, the minimum between either the age of the hotel or the time that has elapsed since the hotel was last refurbished, Age. This variable is included in log form in the regressions, as consumers value more age differences between newer than between older hotels. As quality is a long run decision, we consider it as exogenous when the hotel sets its price every period. ${ }^{6}$

For the purpose of this paper, the most important independent variable is the one describing multimarket contact. To proxy this variable, we take every hotel in every market $k$ (the focal market) and we aggregate the contacts that this hotel has in other markets $m$ (the contact markets) with its market $k$ competitors, given different weights to the contact depending on the characteristics of the market where it takes place. In particular, we weight each contact by a measure of concentration in the contact market, $H I$, because the fewer firms in the market, the softer the competition and the higher the profits. Given that punishments started in more concentrated markets affect firms' profits more negatively, firms care more about these contacts. ${ }^{7}$ Then, we aggregate the number of contacts with each competitor from the focal market and divide this value by the number of rival firms in the focal market, thus providing the firm's average multimarket contact with its rivals in that market, $A V M M C_{i k}$.

Provided with this measure of multimarket contact and defining $\Omega\left(M M C_{i k}\right)=\log \Gamma\left(M M C_{i k}\right)$, we consider two different specifications for $\Omega\left(M M C_{i k}\right)$. Firstly,

$$
\Omega\left(M M C_{i k}\right)=\beta_{1} A V M M C_{i k},
$$

which is independent of the characteristics of the focal market. This specification can allow us to test the sign and significance of the effect that the variable measuring multimarket contact has on prices in average terms. A positive and significant sign for $\beta_{1}$ would be consistent with the traditional view on multimarket contact, but it could also be measuring the effects of omitted variables highly related to multimarket contact, such as the establishment size or its perceived quality.

\footnotetext{
${ }^{6}$ In a previous specification of the empirical model, we also included a dummy variable equal to 1 for firms working with tour operators and 0 otherwise. We dropped this variable out from the final specification presented here since it was not significant in the regressions.

${ }^{7}$ We contrast this variable against an alternative variable that gives the same weight to all the contacts and we reject the null hypothesis that giving different weights to the contacts does not improve the goodness of the estimation.
} 
Secondly,

$$
\Omega\left(M M C_{i k}\right)=\beta_{k} A V M M C_{i k}
$$

where the assumption in (4) is now relaxed to allow for heterogeneity of the multimarket contact effect across markets. The effect of a specific contact in market $k$ can be stated as a function of the ease of collusion in the market, measured by $H I_{k}$, in a way which represents the transfer of market power. We use $H I_{k}$, which is an instrument for the Herfindahl index of concentration, to measure ease of collusion since most models of oligopolistic competition forecast that the higher the market concentration, the more collusive the output of the repeated game. ${ }^{8}$ Following Gimeno and Woo [1995], we specify $\beta_{k}$ as

$$
\beta_{k}=\beta_{1}+\beta_{2} H I_{k}
$$

Therefore, we can rewrite (5) as

$$
\Omega\left(M M C_{i k}\right)=\beta_{1} A V M M C_{i k}+\beta_{2} H I_{k} A V M M C_{i k}
$$

According to Bernheim and Whinston [1990], we expect to observe $\beta_{1}>0$, which means that in markets with a small capacity for collusion, i.e., low $H I_{k}, M M C$ has a positive effect on prices. This effect has to decrease as the ease of collusion, measured by $H I_{k}$, increases, and we thus expect $\beta_{2}<0$. Additionally, we expect $\beta_{k}$ to be equal to zero for a value of $\mathrm{HI}_{k}$ between the minimum and the maximum values in our set of observations. Summing up, the effect of multimarket contact is expected to be greater in absolute terms if the variable measuring the ease of collusion in the focal market, $H I_{k}$, is among either the largest or the smallest in the sample, being positive in markets with very low values for $H I_{k}$ and negative in markets with very high values for $\mathrm{HI}_{k}{ }^{9}$

Accordingly, the price equation can be specified as follows

$$
\begin{aligned}
\log \left(\text { Price }_{i k}\right)= & \beta_{0}+\Omega\left(M M C_{i k}\right)+\beta_{3} \log \left(\text { DD }_{k}\right)+\beta_{4} \log \left(\text { Wages }_{k}\right) \\
& +\beta_{5} \text { Dist }_{i k}+\beta_{6} \text { HI }_{k}+\beta_{7} \text { Category }_{i k}+\beta_{8} \log \left(\text { Age }_{i k}\right)+v_{i k}
\end{aligned}
$$

where $\Omega\left(M M C_{i k}\right)$ is specified above and $v_{i k t}$ is the error term.

\footnotetext{
${ }^{8}$ We have also tried other variables but they provided either worse or insignificant results. These variables are the following. First, the rate of demand growth since rapid growth makes the consequences of punishment (which occurs in the future) more important relative to the gain from deviating (which is instantaneous). So, in a market with high growth rate, the ease of collusion is expected to be greater. Second, the variance of the demand and, third, the entry of new competitors in the market during the last two years since higher instability of demand or a large proportion of entries make collusion more difficult. See Tirole [1988, pp. 245-253] for a more detailed explanation regarding the effects of these variables on the ease of collusion.

${ }^{9}$ We have also tested more complicated specifications, such as quadratic functions, for the term measuring multimarket contact but the main results remained unchanged.
} 
We estimate the model applying generalized least squares after finding that the residuals from the ordinary least squares estimation were heteroscedastic according to the Breusch and Pagan test.

\section{RESULTS AND INTERPRETATION}

Table I provides the results of estimating the empirical model. Column (1) presents the results for the price equation (7) assuming that there are no multimarket contact effects, i.e., when $\Omega\left(M M C_{i k}\right)$ is not included in the regression. The interest of this equation is twofold. First, it tests the suitability of the model for the Spanish hotel industry. Second, it allows us to compare these results with those that we obtain after introducing multimarket contact effects in the model and to study misspecification effects on the estimates. The coefficients for all the variables, except $H I$, are significant and have the expected signs. The price is higher in hotels which are newer and of a higher category, which

TABLE I

Price EQuation

DePendent VARIABLE $=\log \left(\right.$ Price $\left._{i k}\right)$

Generalized Least Squares

\begin{tabular}{|c|c|c|c|}
\hline Independent variable & (1) & (2) & (3) \\
\hline Constant & $\begin{array}{c}2.03 \\
(2.48)\end{array}$ & $\begin{array}{l}1.67 \\
(2.04)\end{array}$ & $\begin{array}{c}1.77 \\
(2.17)\end{array}$ \\
\hline $\log \left(D D_{k}\right)$ & $\begin{array}{c}0.01 \\
(3.27)\end{array}$ & $\begin{array}{c}0.02 \\
(4.25)\end{array}$ & $\begin{array}{c}0.02 \\
(4.20)\end{array}$ \\
\hline $\log \left(\right.$ Wages $\left._{k}\right)$ & $\begin{array}{c}0.52 \\
(7.75)\end{array}$ & $\begin{array}{c}0.54 \\
(8.09)\end{array}$ & $\begin{array}{c}0.53 \\
(8.02)\end{array}$ \\
\hline Dist $_{i k}$ & $\begin{array}{c}0.37 \\
(3.21)\end{array}$ & $\begin{array}{c}0.37 \\
(3.24)\end{array}$ & $\begin{array}{c}0.36 \\
(3.11)\end{array}$ \\
\hline$H I_{k}$ & $\begin{array}{c}0.14 \\
(1.23)\end{array}$ & $\begin{array}{c}0.17 \\
(1.52)\end{array}$ & $\begin{array}{c}0.22 \\
(1.91)\end{array}$ \\
\hline Category $_{i k}$ & $\begin{array}{c}0.38 \\
(24.54)\end{array}$ & $\begin{array}{c}0.37 \\
(23.51)\end{array}$ & $\begin{array}{c}0.37 \\
(23.40)\end{array}$ \\
\hline $\log \left(A g e_{i k}\right)$ & $\begin{array}{l}-0.03 \\
(-3.21)\end{array}$ & $\begin{array}{l}-0.03 \\
(-3.99)\end{array}$ & $\begin{array}{l}-0.03 \\
(-3.91)\end{array}$ \\
\hline$A V M M C_{i k}$ & & $\begin{array}{c}0.22 \\
(5.69)\end{array}$ & $\begin{array}{c}0.38 \\
(5.36)\end{array}$ \\
\hline$H I_{k} A V M M C_{i k}$ & & & $\begin{array}{l}-1.95 \\
(-3.07)\end{array}$ \\
\hline Adjusted $R^{2}$ & 0.41 & 0.42 & 0.42 \\
\hline $\begin{array}{l}F(\cdot) \\
\text { Degrees of freedom }\end{array}$ & $\begin{array}{c}257.80 \\
(6,2214)\end{array}$ & $\begin{array}{c}227.20 \\
(7,2213)\end{array}$ & $\begin{array}{c}200.15 \\
(8,2212)\end{array}$ \\
\hline No. of observations & 2221 & 2221 & 2221 \\
\hline
\end{tabular}

Note: $t$-tests in parenthesis. 
face a more inelastic demand, and in areas where wages and demand are higher. It is important to notice that the coefficient of the concentration variable, $H I$, is not significant, although its sign is as expected, suggesting that in this industry, concentration has no effect on prices. However, this may be due to the omission of the multimarket contact variable. So, the erroneous specification of the model would lead to wrong conclusions.

Column (2) presents the results of estimating the price equation (7) when we include multimarket contact defined as in equation (4), i.e., when its effect is independent of the characteristics of the focal market. The coefficient for the multimarket variable, $A V M M C$, is positive and significant at a level of $1 \%$. This result suggests that multimarket contact contributes to a reduction in rivalry among the firms in the industry, which is the expected effect according to the traditional view. Nevertheless, the observed positive effect might be due to the fact that hotels having more contacts, which are those belonging to a chain, are bigger on average terms and have more market power owing to their larger size. In fact, this is consistent with the figures on output, employment and number of rooms provided in the Appendix. Another explanation of this effect could be the policy of giving an incentive, usually a free stay, to a frequent customer after she has conducted a certain amount of business with the hotel chain. The obvious way to control for this effect is to include the size of the chain to which the hotel belongs to as an explanatory variable in the regression. However, this is not possible given its high correlation with $A V M M C$ $(\rho=0.74)$. In any case, this significant correlation strongly supports our hypothesis. $^{10}$

Column (3) presents the result of the estimation when we consider the interaction between the ease of collusion in the focal market and multimarket contact as in equation (6), the variable measuring the ease of collusion being $H I$. Our hypothesis focuses on the effects of multimarket contact on markets with a different ease of collusion. According to the theory, in the presence of multimarket contact, prices are expected to fall in markets where it is easier to reach collusive outcomes whilst they are expected to increase where it is more difficult to collude. In order to identify this non-homogeneous effect, a linear interaction between concentration in the focal market and multimarket contact is specified. It can be seen that the coefficient for $A V M M C_{i k}, \beta_{1}$, is positive and the coefficient for $H I_{k}$ $A V M M C_{i k}, \beta_{2}$, is negative, both of them being significant at the $1 \%$ level. The predicted iteration effects are shown in Figure 1 where we can observe that the effect of multimarket contact on price remains positive until $H I_{k}$ reaches the value 0.19 . Given that the sample average for $H I_{k}$ is 0.16 and

\footnotetext{
${ }^{10}$ See Gimeno and Woo [1994] for a test of these effects on the unidirectional coefficient of $A V M M C$.
} 


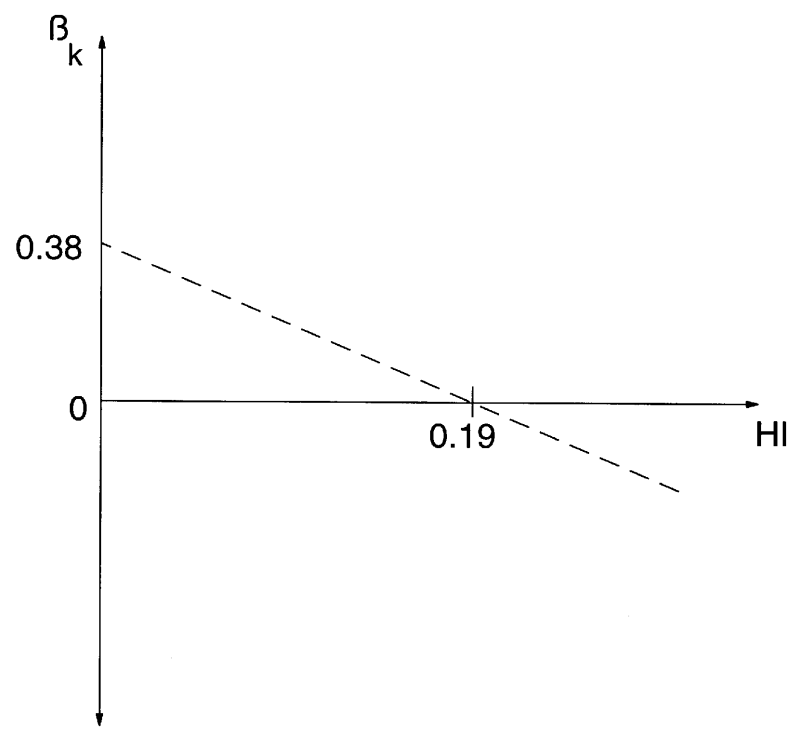

Note: Ease of collusion is measured by the variable $\mathrm{HI}$

Figure 1

Ease of collusion effect on prices through multimarket contact

the sample median value is 0.09 , this result gives strong support to Bernheim and Whinston's [1990] predictions.

We should also notice that once we have introduced the multimarket contact variables the coefficient of $H I$ becomes significant. This suggests that the previous conclusions about the role of concentration in the industry resulted from a misspecification of the model. In fact, once we control for the multimarket contact strategic effects, we observe that prices are significantly higher in more concentrated markets

We have estimated the same three regressions for each of the five different categories in the sample ${ }^{11}$ and the main results hold for each subsample, though some variables become less significant mainly due to the small number of observations for some categories.

\section{CONCLUSIONS}

The hypothesis that multimarket contacts increase the ability of firms to attain and sustain tacit collusive agreements in any single market was articulated for the first time in Edwards [1955]. In a recent theoretical contribution,

${ }^{11}$ In these regressions we omitted the variable Category from the regression. 
Bernheim and Whinston [1990] provide some guidance as to appropriate strategies for empirically examining the effects of multimarket contact.

In this paper, we examine the effects of multimarket contact on pricing in the Spanish hotel industry. In particular, we estimate a reduced form price equation which depends on market and firm characteristics, future expectations and multimarket contact, taking as given variables involving firms' long run decisions. This approach suffers from two limitations that could not be solved because of the nature of the data. Firstly, we could not incorporate data on demand variables so that we could not estimate the structural parameters from the price and demand equations and secondly, the analysis could not be extended in order to incorporate dynamic aspects and endogenize long run decision variables.

Despite these shortcomings, it is possible to derive two relevant results from our analysis. Firstly, it reveals that the omission of variables measuring multimarket contact creates a downward bias on the effect of concentration on prices. Hence in industries where multimarket contact takes place, this type of erroneous specification in modelling the behavior of the firms may lead to a wrong conclusion about the strength of firms' market power in the industry.

Secondly, we find relevant strategic multimarket effects. In particular, in the presence of multimarket contact, prices are higher in markets where it is difficult to collude and lower in markets where collusion is easier to achieve. Thus, we interpret our results as evidence supporting Bernheim and Whinston's [1990] hypothesis in the context of this industry. To our knowledge this is the first time that this hypothesis has been purposely empirically tested and significant results have been found. This implies that antitrust authorities should worry not only about mergers that increase market concentration but also about those that increase multimarket contact among the firms operating in the market, even if market concentration remains unchanged. In other words, multimarket contact should be taken into account when taking antitrust decisions.

\section{APPENDIX: THE DATA AND DEFINITIONS OF THE VARIABLES}

The sample is taken from the 1996 Spanish Professional Hotel Guide published by the Instituto de Estudios Turisticos (Institute of Tourist Studies). This data base includes 9482 establishments, distributed in the following categories: vacation city, hotel, apartment hotel, residential hotel, boarding house, residential boarding house, motel, and apartment residence. Given the heterogeneity of the services provided by these establishments, we center the study on a segment of the industry which only includes hotels and boarding houses with 3 or more stars. If we reject those establishments with incomplete data or having been built before 1900 and never having been refurbished, we obtain a cross section sample with 2221 hotels and boarding houses. 
The establishments classified as hotels include independent $(82.2 \%)$ and non independent hotels (17.8\%). Establishments in the second group belong to 106 different hotel chains. In 1994, the hotel industry gave employment to 159,000 persons and its output, which is defined as the set of incomes generated from the different types of services they offer, had a value of approximately 7,600 million dollars, representing $1.4 \%$ of the Spanish GDP. Hotels belonging to chains represented $35 \%$ and $43 \%$ of total employment and output, respectively. Thus on average, establishments belonging to a chain are larger than independent hotels.

Table AI shows the age distribution of the establishments included in the sample. We can see that more than two thirds of them are more than 4 years old. Table AII presents the distribution between independent and chain hotels by number of establishments and bed capacity and shows that almost one half of 4-5 star hotels belong to a hotel chain while for 3 star hotels this percentage falls to one third. In particular, in our sample $32.8 \%$ of the establishments belong to a chain. The figures on the number of rooms also show that chain hotels are on average larger than independent hotels. Finally, Table AIII shows the size distribution of the 106 chains operating in Spain according to the Professional Hotel Guide. More than one half

TABLE AI

Age Distribution of Establishments

\begin{tabular}{lccccc}
\hline Age & No. of Establishments & $\%$ & 3 & 4 & 5 \\
\hline Less than 5 years & 721 & 0.32 & 480 & 218 & 23 \\
5 to 9 years & 607 & 0.27 & 417 & 173 & 17 \\
10 to 20 years & 261 & 0.11 & 183 & 73 & 5 \\
More than 20 years & 632 & 0.28 & 522 & 99 & 11 \\
\hline
\end{tabular}

TABLe AII

Distribution Between Independent and Chain Hotels by Number of ESTABLISHMENTS AND CAPACITY

\begin{tabular}{lrcrc}
\hline Stars & $\begin{array}{c}\text { No. of } \\
\text { hotels }\end{array}$ & $\begin{array}{c}\text { \% of hotels belonging } \\
\text { to a chain }\end{array}$ & $\begin{array}{c}\text { No. of } \\
\text { rooms }\end{array}$ & $\begin{array}{c}\text { \% of rooms in hotels } \\
\text { belonging to a chain }\end{array}$ \\
\hline 5 & 62 & 48.4 & 11,830 & 57.3 \\
4 & 616 & 51.3 & 103,058 & 55.2 \\
3 & 1,721 & 28.1 & 211,781 & 40.1 \\
2 & 1,511 & 4.8 & 83,897 & 14.0 \\
1 & 1,383 & 2.8 & 47,129 & 14.4 \\
Total & 5,293 & 17.8 & 457,695 & 36.5 \\
\hline
\end{tabular}

Note: This sample only includes establishments classified as hotels.

Table AIII

Size Distribution of Hotel Chains

\begin{tabular}{lr}
\hline Less than 5 hotels & 58 \\
5 to 19 hotels & 38 \\
20 to 49 hotels & 6 \\
50 to 99 hotels & 3 \\
More than 99 hotels & 1 \\
\hline
\end{tabular}


of the chains are small, with less than five establishments, but the four largest chains have more than 50 establishments each. This fact gives an idea about the important differences in multimarket contact across chains.

As Evans and Kessides [1994] suggest: 'In empirical tests of the multimarket contact hypotheses, an appropriate definition of the market is of paramount importance.' In the case of the Spanish hotel industry, markets are quite well defined, and there is little ad hoc intervention on the part of the researcher. This is because the Spanish National Institute of Statistics, and the corresponding Department of Tourism of each regional administrative unit provide a division of the Spanish territory in 83 different geographic markets according to the tourism and business characteristics of their different areas. In particular, the main business and tourist towns (such as Madrid, Barcelona, Valencia, Granada, Benidorm and Marbella among others) and mountainous areas are regarded as independent markets. Moreover, in coastal provinces, towns are split into inner and seafront areas, and the Balearic and Canary Islands are divided into different islands and also according to the criteria mentioned above.

The Professional Hotel Guide provides data at hotel level including the following information: city and location in the city that can be either the city center or the outskirts, year of construction or last renovation, number of beds and rooms, prices of all types of rooms, number of stars of the hotel, services provided by the hotel (swimming pool, conference room, 24 hours service, etc.), equipment in the bedroom (TV, hi-fi set, minibar, hair dryer, etc.), whether the establishment belongs or not to a chain, and if it does, to which, and whether the hotels works with tour operators or not. Data on wages and market demand have been provided by the Bank of Spain Research Department, the Spanish National Institute of Statistics and the corresponding Department of Tourism of each regional administrative unit.

Given this information, we calculate the following variables:

Age.- 1996 minus the year of construction or last renovation. We take logs of this variable so we value more the age differences in newer than in older hotels.

Category.- Dummy variable with values ranging from 1 to 5 constructed by ordering the hotels in five categories from lower to higher as follows: 3 stars-silver, 3 stars-gold, 4 stars-gold, 5 stars-gold and 5 stars-luxury.

DD.- Number of stays in 1994 disaggregating by geographical markets, except for Balearic Islands.

Dist.- We construct this variable measuring quality distance as

$$
\text { Dist }_{i k}=\frac{\sqrt{\sum_{j \neq i}\left(\text { Categor }_{i}-\text { Categor }_{j}\right)^{2}}}{\sqrt{16(N-1)}}
$$

This variable measures the average distance in terms of category between each hotel and its competitors in the market and it is normalized by the maximum possible distance in that specific market. ${ }^{12}$

HI.- Instrument for the Herfindahl index of concentration which is constructed using installed capacity for each establishment, where installed capacity is regarded as an instrument for sales.

\footnotetext{
${ }^{12}$ We have also calculated measures of spatial distance and size distance which we do not include in the final specification of the model because either they are not significant or they are correlated with other relevant explanatory variables.
} 
Multimarket Contact.- An instance of multimarket contact occurs, according to our definition, when a hotel $i$ and its competitor $j$ in the focal market $k$, also meet in a different market $m$. If an event of multimarket contact occurs Contact $_{i j, k m}=1$,

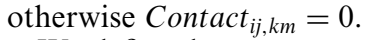

We define the measure of multimarket contact, $M M C$, as

$$
M M C_{i j, k m}=\text { Contact }_{i j, k m} H I_{m}
$$

i.e., we assign a different value to the contacts depending on the degree of concentration in the contact market $m$.

The measure of multimarket contact is the weighted average number of multimarket contacts with the competitors in the focal market which is calculated as follows:

$$
A V M M C_{i k}=\frac{1}{T C_{i k}} \sum_{j \neq i} \sum_{m \neq k} M M C_{i j, k m}
$$

where $T C_{i k}$ is the number of firm $i$ 's competitors in the focal market.

Price.- High season price of a double room (VAT not included) with a full bathroom. The reason for choosing this specific price is that this type of room is most representative of the sample and low season prices are significantly correlated to high season prices $(\rho=0.91)$.

Wages.- Wages for the 4th quarter of 1994, disaggregated by administrative regions, computed as the total payment per worker per month.

\section{REFERENCES}

Bernheim, D. and Whinston, M. D., 1990, 'Multimarket Contact and Collusive Behavior', Rand Journal of Economics, 21, pp. 1-26.

Edwards, C. D., 1955, 'Conglomerate Bigness as a Source of Power' in The National Bureau of Economic Research Conference Report, Business Concentration and Price Policy (Princeton: Princeton University Press), pp. 331-359.

Evans, W. N. and Kessides, I. N., 1994, 'Living by the "Golden Rule": Multimarket Contact in the US Airline Industry', Quarterly Journal of Economics, 109, pp. 341-366.

Gimeno, J. and Woo, C. Y., 1994, 'Multimarket Competition, Market Rivalry and Firm Performance: A Critical Test of the Mutual Forbearance Hypothesis and Alternative Explanations', Proceedings of the Academy of Management Meeting.

Gimeno, J. and Woo, C. Y., 1995, 'Multimarket Contact as a Mechanism of Transfer of Power Across Structurally Different Markets'. Working paper. Department of Management. Texas A\&M University.

Karnani, A. and Wernerfelt, B., 1985, 'Multiple Point Competition', Strategic Management Journal, 6, pp. 87-96.

Parker, P. M. and Röller, L. H., 1997, 'Collusive Conduct in Duopolies: Multimarket Contact and Cross-Ownership in the Mobile Telephone Industry', Rand Journal of Economics, 28, pp. 304-322.

Phillips, R. P. and Mason, C. F., 1992, 'Mutual Forbearance in Experimental Conglomerate Markets', Rand Journal of Economics, 23, pp. 395-414.

Sutton, J., 1991, Sunk Costs and Market Structure, (The MIT Press).

Tirole, J., 1988, The Theory of Industrial Organization, (The MIT Press). 